\author{
Marquette University \\ e-Publications@Marquette
}

College of Nursing Faculty Research and

Publications

Nursing, College of

$12-2012$

\title{
Children With Developmental Disabilities at a Pediatric Hospital: Staff Education to Prevent and Manage Challenging Behaviors
}

Norah L. Johnson

Marquette University, norah.johnson@marquette.edu

Joel Lashley

Children's Hospital of Wisconsin

Alice V. Stoneck

Children's Hospital of Wisconsin

Annette Bonjour

Children's Hospital of Wisconsin

Follow this and additional works at: https://epublications.marquette.edu/nursing_fac

Part of the Nursing Commons

\section{Recommended Citation}

Johnson, Norah L.; Lashley, Joel; Stoneck, Alice V.; and Bonjour, Annette, "Children With Developmental Disabilities at a Pediatric Hospital: Staff Education to Prevent and Manage Challenging Behaviors" (2012). College of Nursing Faculty Research and Publications. 117.

https://epublications.marquette.edu/nursing_fac/117 
Marquette University

e-Publications@Marquette

\section{Nursing Faculty Research and Publications/College of Nursing}

This paper is NOT THE PUBLISHED VERSION; but the author's final, peer-reviewed manuscript. The published version may be accessed by following the link in the citation below.

Journal of Pediatric Nursing, Vol. 27, No. 6 (December 2012): 742-749. DOI. This article is (C) Elsevier and permission has been granted for this version to appear in e-Publications@Marquette. Elsevier does not grant permission for this article to be further copied/distributed or hosted elsewhere without the express permission from Elsevier.

\section{Children with Developmental Disabilities at a Pediatric Hospital: Staff Education to Prevent and Manage Challenging Behaviors}

Norah L. Johnson

Children's Hospital of Wisconsin, Milwaukee, WI

College of Nursing, Marquette University, Milwaukee, WI

Joel Lashley

Children's Hospital of Wisconsin, Milwaukee, WI

Alice V. Stonek

Children's Hospital of Wisconsin, Milwaukee, WI

Annette Bonjour

Children's Hospital of Wisconsin, Milwaukee, WI

Children with developmental disabilities may get frustrated in unpredictable hospital environments. Frustration may escalate to challenging behaviors, which are a safety concern and may contribute to staff and patient injuries, use of restraints, and procedure delay or cancelations. The purpose of this article was to describe a pilot staff education program on preventing and managing challenging 
behaviors of children with developmental disabilities at a pediatric hospital. The 2-hour-long education ( 1 hour on-line and 1 hour instructor led) content focused on family-centered care and communication skills, including verbal judo ${ }^{\mathrm{TM}}$ modified for use in the health care setting. Participants in the instructorled sessions reported improved knowledge and decreased fear about caring for children with developmental disabilities. Relationships of the education and fewer staff injuries, fewer canceled procedures, and decreased use of restraints merit further study.

\section{Key words}

Challenging behaviors, Children, Developmental disabilities, Autism, Communication

DEVELOPMENTAL DISABILITIES ARE a diverse group of severe chronic conditions that are because of mental and/or physical impairments (Centers for Disease Control and Prevention [CDC], 2004). They affect language, mobility, learning, self-help, and independent living (CDC, 2004).The impairments associated with developmental disabilities place children at risk for frustration and subsequent challenging behaviors in the often overwhelming, noisy, unpredictable hospital environment (Debbaudt, 2009, Klaw, 2006, Scarpinato et al., 2010, Souders et al., 2002). Bruininks, Woodcock, Weatherman, and Hill (1997) classify challenging behaviors into three categories: (a) lack of cooperation with instructions, (b) internalized behaviors (withdrawal, repetitive habits, and self-injury), and (c) externalized behaviors (tantrums, being disruptive, being hurtful to others, and damaging property). Nursing staff finds caring for children with these challenging behaviors difficult. They struggle with knowing appropriate approaches to safe and timely care. The purpose of this article was to describe a pilot staff education program on preventing and managing challenging behaviors of children with developmental disabilities at a pediatric hospital.

\section{Background}

Developmental disabilities are estimated to affect $17 \%$ of children less than 18 years of age in the United States (CDC, 2006). Individuals with developmental disabilities have more hospital admissions than typically developing children (Liptak, Stuart, \& Auinger, 2006). These disabilities may include autism spectrum disorder (ASD), cerebral palsy, Down syndrome and other congenital abnormalities, vision and hearing impairments, and mental retardation. Evidence suggests that children with ASD have the most challenging behaviors (Estes et al., 2009, Newsom and Hovanitz, 2006) and associated anxiety (Gurney, McPheeters, \& Davis, 2006) of all the developmental disabilities. The hospital environment may overwhelm the child's sensory system and contribute to the development of challenging behaviors (Aylott, 2004, Debbaudt, 2009). Children on behavior/mood medications such as antipsychotic, antihypertensive, or seizure medications and those with a history of violence, disruptive behavior, or alternative placements also are prone to challenging behaviors in overwhelming environments (Lashley, 2009).

Although children with developmental disabilities such as ASD have similar basic medical needs as children without any developmental disabilities, meeting their needs can be more challenging (Myers \& Johnson, 2007) because of their struggle with routine changes and new environments (Scarpinato et al., 2010, Souders et al., 2002). Children may flee a clinic setting out of fear, causing a security problem 
in hospitals (Allik et al., 2006, Debbaudt, 2009, Scarpinato et al., 2010, Tarbox et al., 2003). Injuries and procedure delay or cancelation may result.

\section{Problem}

Literature shows that direct care staff members, such as nurses and care partners, who encounter children with developmental disabilities and challenging behaviors may lack the necessary knowledge and skills to manage the behaviors, may be fearful of caring for these children (Baker, 2008), and are themselves at risk for injury (Debbaudt, 2009). Security personnel approached the education services department at a 296-bed midwestern pediatric hospital with concerns about the challenging behaviors of children with developmental disabilities and their desire to support them better. Although it is a Joint Commission standard to assure safety and limit use of physical restraint in the acute care hospital setting (The Joint Commission, 2011), individual organizations' responses to this Joint Commission goal may vary in approach and effectiveness. Health care providers struggle with the ethical implications of using restraints to gain compliance and were in some cases hesitant to use them (Loo et al., 2009, Thorne, 2007).

\section{Intended Improvement}

Following institutional process, staff in key positions (security personnel, nurses, physicians, child life specialists, and other direct-care health care providers) developed a program to prevent and manage challenging behaviors by children with developmental disabilities. The aims of the program were to prevent and manage challenging behaviors and to decrease staff fear of caring for children with developmental disabilities. Review of research, clinical practice articles, and lay literature revealed no standardized staff education program and led to the hypothesis that the biggest area of need for training was how to communicate with children with developmental disabilities. Therefore, the educational training focused on two areas: (a) family-centered care to prevent challenging behaviors (Hockenberry \& Wilson, 2010) and (b) communication strategies both to prevent and manage challenging behaviors, based on verbal judo (Thompson \& Jenkins, 2004), modified with permission (Lashley, 2009, Thompson and Jenkins, 2004) for the health care setting.

\section{Family-Centered Care}

Strategies based on family-centered care promote the prevention of challenging behaviors in the hospital setting (Carbone et al., 2010, Kogan et al., 2008). Family-centered care consists of values, attitudes, and approaches to services for families of children with special needs (Hockenberry \& Wilson, 2010). Family-centered service recognizes that each family is unique, that the family is the constant in the child's life, and that the family is the expert on the child's abilities and needs (Hockenberry \& Wilson, 2010). For children with developmental disabilities such as ASD, familycentered care includes as much individual assessment of the child as possible, prior to their hospital appointment or hospitalization. During this assessment, nurses should inquire about the child's likes and dislikes, what upsets them, and how best to communicate with the child (Blake, 2010).

Once in the hospital, children with ASD need time to become familiar with the environment before requesting their compliance (Debbaudt, 2009, Myers and Johnson, 2007, Scarpinato et al., 2010). Children with ASD like a quiet, low-stimulation environment. Nurses should speak to the child slowly, 
one person at a time, using simple, concrete language, for example, "want water," "sit in chair," "do this," "hands quiet," " all done?" (Scarpinato et al., 2010). Once the child complies with instructions, the nurse should offer praise to the child as a reward for the desired behavior (Thorne, 2007).

Parents are encouraged to stay with their child in the hospital because they know their child's behavior triggers best. Children should be prepared for transitions and procedures with a positive approach, including step-by-step instructions paired with pictures, videos, and sensory toys for distraction (Bellando and Lopez, 2009, Browne, 2006, Giarelli et al., 2005, Raposa, 2009, Scarpinato et al., 2010, Thorne, 2007, Tucker et al., 2008). One method of procedure preparation is the social story ${ }^{\mathrm{TM}}$. The social story format is used to break procedures into small steps (Gray, 1994). The story is reviewed with the child before a procedure in order to provide social information about a situation to help decrease the child's anxiety and improve his or her ability to cooperate with instructions. More information about social stories can be found at www.thegraycenter.org. Social stories may be shared at any time, as long as the stories are not exchanged for a fee (Gray, 2012).

\section{Communication}

Communication techniques for preventing and managing challenging behaviors were located in the literature. Tantrums, also known as behavioral outbursts or rage, have three stages: rumbling, rage, and recovery (Smith-Myles \& Southwick, 2005). Tantrums may be precipitated a variety of causes, such as frustration, pain (Gardner, 2001), excess sensory input, and changes in schedule (Debbaudt, 2009, Valente, 2004). In fact, children with developmental disabilities such as ASD thrive on ritual and routine. When their routine is interrupted, a tantrum may result (Inglese, 2009, Scarpinato et al., 2010, Thorne, 2007).

In addition, children with ASD have other behaviors that should not be interrupted. At baseline, children with ASD deal with anxiety by self-stimulatory behaviors, for example, rocking, known as stiming (Smith-Myles \& Southwick, 2005). Other behaviors classified as stiming include twisting hands, flapping hands, blinking eyes, making noises, biting objects, and making repetitive movements (BeardPfeuffer, 2008). Sometimes, the stiming behaviors progress and include a destructive element. The progression, called rumbling, indicates that the child is more anxious and likely to have an outburst (Smith-Myles \& Southwick, 2005). Rumbling is increased vocal and physical signs of escalating hand flapping, rocking, jumping, foot tapping, pacing, or humming. It tends to progress to rage in cases where the care provider continues to make demands of the child. This rage (also known as a tantrum or a meltdown) includes screaming, biting, hitting, kicking, and running off. After the tantrum happens, the child enters a calming stage known as recovery, where he or she may sleep, deny that the tantrum happened, or may apologize if he or she has sufficient communication skills (Smith-Myles \& Southwick, 2005).

Adult reaction to the rumbling child directly impacts the progression to rage (Smith-Myles \& Southwick, 2005). Reducing demands and quieting the child's environment significantly decrease the likelihood of rage (Smith-Myles, \& Southwick, 2005). Staff education should focus on recognizing rumbling behavior and reducing demands on the child. Further, the nurse should not block any selfstimulatory behavior such as hand flapping (Debbaudt, 2009, Lashley, 2009). In addition, the nurse should not invade the child's personal space and should limit loud noises, alarms, and clutter 
(Scarpinato et al., 2010, Thorne, 2007). Nurses should use clear language, avoid the word no, and refrain from insisting on eye contact, as this is stressful for some children (Browne, 2006). After speaking with a child, pausing is recommended to allow time for the child to process language (Scarpinato et al., 2010). Augmented and alternative communication methods such as picture exchange communication system can help calm the child by allowing them to communicate their wishes (Scarpinato et al., 2010).

Verbal judo is a communication technique designed for use in police work for deescalating tense situations by structuring communication (Thompson \& Jenkins, 2004). The process involves informing a client about what is happening rather than using physical force to gain compliance with police instructions. Specifically, the structured communication includes informing the person about your name, role, what is going on, what you are going to do, and then using a closing statement such as "good job." Verbal judo was adapted for use in the health care setting, for use with children with developmental disabilities. The process of giving information to the child with developmental disabilities in this manner is thought to promote peaceful encounters (Thompson \& Jenkins, 2004).

\section{Question}

This evaluation of the education on challenging behaviors addresses one of the aims of the education with the following question: Do nursing staff and students who receive the training have increased knowledge and decreased fear of working with children with developmental disabilities, as measured on a 10-point Likert scale? The second aim of the program, determining if the use of the communication strategies in the training led to the decreased staff injury or use of restraints, was beyond the scope of the present program.

\section{Theoretical Framework}

The education program was framed on self-efficacy theory (Bandura, 1977). Self-efficacy is defined as a person's belief in his or her ability to perform a designated task. In order for nurses to use the proactive and reactive strategies, they would need to perceive that the strategies were useful for improving communication, providing distraction, and decreasing a child's anxiety and challenging behaviors. The overall guidance for the development of the education came from the principles of effective instructional programs: (a) providing relevant information, (b) the demonstration of knowledge, (c) opportunity to practice, and (d) feedback to trainees, after practice (Salas \& CannonBowers, 2001).

\section{Methods}

\section{Ethical Issues}

Led by a staff development advanced practice nurse, the multidisciplinary team of security personnel, nurses, physicians, child life specialists, and other direct-care health care providers created the staff education program designed to prevent and handle the challenging behaviors of children with developmental disabilities at a pediatric hospital. Most of the team members had both personal and professional experience working with children with developmental disabilities. Careful attention was given to literature as the basis for the education program question, hypothesis, and content. The 
education included videos of children with ASD in health care settings. Parents of children with ASD who participated in the videos signed release forms.

\section{Setting}

The program was designed to be part of a new nursing staff central orientation at a midwestern pediatric hospital. Central orientation content reflects current trends in educational needs for nursing staff and is updated based on trends in health care. Therefore, piloting the education by offering it in central orientation was deemed most likely to influence the desired improvement in knowledge and decrease in fear for caring for the children.

\section{Planning the Intervention}

Proactive strategies were designed to prevent the escalation of frustration to the presentation of challenging behaviors. Reactive strategies were designed to handle the challenging behaviors that were not prevented. Educational objectives were developed for the two-part education (on-line and the instructor led) content. Both parts of the education were piloted for new nursing and care-partner staff as part of a new employee hospital orientation. In addition, managers in the neurosciences and the emergency department assigned the on-line education to the nurses and invited the behavioral challenges class instructors to their regularly scheduled staff development education days to teach the instructor-led portion of the education. The managers could also enroll their current employees for the central hospital orientation version of the instructor-led classes.

\section{Delivery Mechanism}

All staff completed 2 hours of education, broken up into a 1-hour on-line education to deliver information and a 1-hour-long instructor-led class that provided staff time to practice communication skills necessary to promote confidence and self-efficacy (Badura, 1977). The class was co-taught by security personnel, child life specialists, and nurses. The aim of the class was to improve confidence of health care providers because they may fear confrontation or feel intimidated in busy hospital environments (Fontaine \& Gerardi, 2005). The instructor-led classes allowed staff an opportunity to demonstrate knowledge, practice strategies, and receive instructor feedback.

\section{Part 1: On-line Education}

Eight learning objectives were covered in four 15-minute-long case-based lessons on the health system's on-line learning platform (Table 1).The on-line lessons were designed to deliver background knowledge in a convenient format that would be supplemented with the instructor-led class. The lessons included (a) an overview of developmental disabilities, with a focus on ASD; (b) preparation strategies; (c) communication strategies; and (d) play strategies. Training for children with ASD was highlighted because children with ASD often have the most challenging behaviors in the hospital

environment. However, all the techniques and modifications in the education and supporting items are suitable for all children with developmental disabilities, as the modifications support calm communication and family-centered care. 
Table 1. On-line Education Survey Results $(n=603)^{*}$

\begin{tabular}{|c|c|c|c|c|c|c|}
\hline & $\begin{array}{l}\text { Strongly } \\
\text { Disagree, \% (n) }\end{array}$ & $\begin{array}{l}\text { Disagree, } \\
\%(n)\end{array}$ & $\begin{array}{l}\text { Neutral, } \\
\%(n)\end{array}$ & $\begin{array}{l}\text { Agree, \% } \\
(n)\end{array}$ & \begin{tabular}{|l|} 
Strongly \\
Agree, \% (n)
\end{tabular} & $\begin{array}{l}\text { Rating } \\
\text { Average }^{\dagger}\end{array}$ \\
\hline \multicolumn{7}{|l|}{ After the On-line Education the Learner Was Able to Identify: } \\
\hline Why this behavioral training is necessary & $2(12)$ & $0.2(1)$ & $2.2(13)$ & $39.3(237)$ & $56.4(340)$ & 4.48 \\
\hline How to prevent challenging behaviors & $1.8(11)$ & $0.2(1)$ & $3(18)$ & $54.9(331)$ & $40.1(242)$ & 4.31 \\
\hline How parents can prepare the child & $1.8(11)$ & $0.2(1)$ & $2.2(13)$ & $45.9(277)$ & $49.8(300)$ & 4.41 \\
\hline How staff can prepare the child & $2(12)$ & $0.2(1)$ & $2.5(15)$ & $47.8(288)$ & $47.6(287)$ & 4.39 \\
\hline Important questions to ask on admission & $2(12)$ & $0.2(1)$ & $3.2(19)$ & $49.4(298)$ & $45.3(273)$ & 4.36 \\
\hline Stages of escalating behavior & $1.8(11)$ & $0.2(1)$ & $2.3(14)$ & $47.8(288)$ & $47.9(289)$ & 4.40 \\
\hline What to do during challenging behaviors & $1.8(11)$ & $0.2(1)$ & $3.6(22)$ & $52.2(315)$ & $42.1(254)$ & 4.33 \\
\hline Toys a child with autism plays with & $1.8(11)$ & $0.3(1)$ & $3.3(20)$ & $48.6(293)$ & $45.9(277)$ & 4.36 \\
\hline \multicolumn{7}{|l|}{ The behavioral challenges on-line lessons ${ }^{\ddagger}$} \\
\hline Were relevant to my practice & $1.7(10)$ & $1.2(7)$ & 7.7 (46) & $48.6(293)$ & 45.9 (277) & 4.28 \\
\hline Will improve my ability to provide excellent patient care & $1.7(10)$ & $0.8(5)$ & $7.5(45)$ & $46.3(278)$ & $43.7(262)$ & 4.30 \\
\hline
\end{tabular}

$*$ One person skipped question.

†Five-point Likert scale, 1 = strongly disagree to 5 = strongly agree .

¥Four persons skipped the question. 


\section{Part 2: Instructor-Led Education}

Objectives for the instructor-led portion of the education (1-hour-long class) were based on the theoretical framework of self-efficacy (Bandura, 1977). They included the participant's self-report of (a) increased knowledge and (b) decreased fear about caring for children with behavioral challenges. The objectives informed six hospital-produced, 2-minute-long videos, which showed typical situations where health care providers encounter children with ASD. The participants in the videos role modeled strategies for preventing or dealing with challenging behaviors.

In the first video, a mother and her child with ASD arrive at an outpatient clinic, check in, and learn that they need to wait. The desk clerk offers the child distraction items (toys), and the child is allowed to roam through the waiting room, acclimating himself to its many items (fish tank, playhouse). Letting the child employ his natural tactile inquisitiveness in experiencing the new objects and the new environment as he waits should prevent challenging behaviors.

In the second video, the goal is to weigh a child and to measure the child's vital signs. To accomplish this goal and prevent frustrating the child, the nurse uses simple, short commands, for example, "stand on scale" and "quiet hands." These simple commands allow a child with ASD to comply for short periods because he or she is familiar with the terms (Lashley, 2009, Scarpinato et al., 2010). The use of simple commands is an effective strategy for accomplishing the goal of one-step procedures, such as vital signs, but other strategies are needed for multistep procedures.

In the third video, the goal is to insert an intravenous line (IV) for a child in the emergency room. In addition to providing distraction items and the opportunity for acclimation, a child life specialist is consulted to prepare the child and the parents for the steps of the IV insertion procedure using an IV social script book. The IV book has pictures and words. The story decreases the child's anxiety and the chance for challenging behaviors, as he knows what to expect.

The fourth video depicts the recommended communication method to be employed during the IV insertion. The method, originally employed in police work to deescalate high-anxiety situations (Thompson \& Jenkins, 2004), was adapted to the multistep insertion process for the IV. Using this adapted eight-step communication method (Figure 1), the nurse successfully inserts the IV, and the child does not display challenging behaviors.

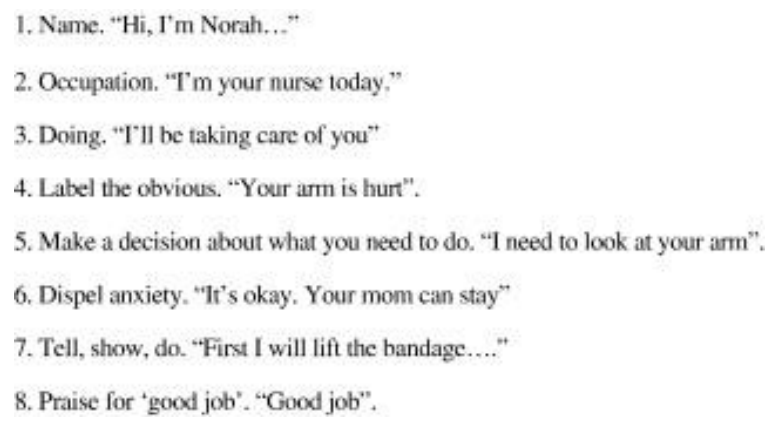

Figure 1. The eight-step communication method (Thompson \& Jenkins, 2004) adapted for use in the health care setting (Lashley, 2009).

1. Name. "Hi, I'm Norah..."

2. Occupation. "I'm your nurse today." 
3. Doing. "I'll be taking care of you"

4. Label the obvious. "Your arm is hurt".

5. Make a decision about what your need to do. "I need to look at your arm".

6. Dispel anxiety. "It's okay. Your mom can stay"

7. Tell, show, do. "First I will lift the bandage...."

8. Praise for 'good job'. "Good job".

The fifth video addresses the relationship between the overstimulation of a child with ASD and his or her challenging behaviors. It begins with a noisy hospital environment with a television on, bright lights, many people talking, and a child with ASD acting out. A security officer enters the room and states, "one voice please," in order to encourage only one person to speak at a time. The child calms down after all nurses stop talking at the same time. Thus, calling for one voice is an effective strategy for reducing stimulation and thereby calming the child.

In the sixth video, the goal was to have a child with ASD comply with instructions to sit down in a chair without acting out. The nurse uses the three-step (asking, waiting, and rewarding) compliance directive cycle developed for use in health care (Lashley, 2009; Figure 2). Specifically, the child was asked to sit while the nurse gestures toward the chair. Next, the nurse waits 11 seconds, and finally, the nurse states, "good job," after the child sits down (Lashley, 2009). The nurse in the video explains that if the child does not sit, after following the three steps, the cycle is repeated. This time, the nurse demonstrates the sitting instead of gesturing to the chair and then gets up from the chair and gestures to the chair while waiting 11 seconds for the child to comply (Figure 2 ). Once the child complies, the nurse says, "good job."

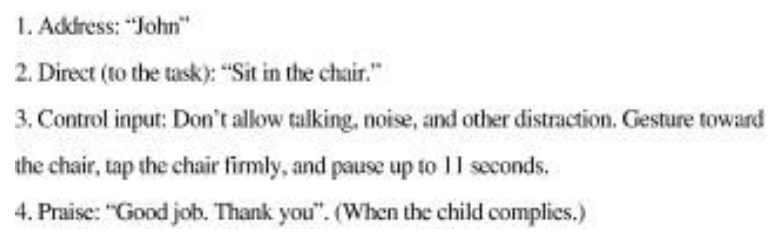

Figure 2. Compliance directive cycle.

1. Address: "John"

2. Direct (to the task): "Sit in the chair."

3. Control input: Don't allow talking, noise, and other distraction. Gesture toward the chair, tap the chair firmly, and pause up to 11 seconds.

4. Praise: "Good job. Thank you". (When the child complies.)

Discussion opportunities followed the showing of each individual video. In addition, after the fourth through sixth video, the participants practiced the communication methods (eight-step, one voice, and compliance directive cycle) with other class participants. Next, the class participants practiced applying the strategies in new situations presented to them as case studies. Staff was then shown how to locate just-in-time teaching sheets, which contain the teaching strategies covered in the videos, on the hospital's intranet.

Staff also learned about an available kit of supporting materials developed for use with children with developmental disabilities. The kit includes several items to assist communication, for example, photos 
of people and equipment so the children know what to anticipate. There are also sturdy plastic chewable toys used for distraction. The kit of supporting materials was evaluated in a research study (Drake, Johnson, Stonek, Martinez, \& Massey, in press) and found useful.

Finally, staff learned about the environmental modifications necessary to meet the needs of children with developmental disabilities at risk for challenging behaviors. These included minimizing lights and noise in and around the patient's room, decreasing clutter and odors, providing sturdy furnishings, and limiting the number of health care providers speaking to the child to one at a time.

\section{Education Evaluation}

The pilot study evaluating the educational objectives was designed as a data-based nonresearch performance improvement project. No institutional review board was needed for the educational evaluation. All staff completed both the on-line and instructor-led education, but each part of the education was evaluated separately in the pilot. The on-line education was evaluated with an on-line survey (5-point Likert scale with the anchors of strongly agree/strongly disagree; Table 1). Data were also collected about staff role (RN or other). Participant comments were also solicited.

\section{Analysis}

The instructor-led education evaluation was voluntary, in-person, before and immediately after five sessions of the instructor-led classes that took place for new employees. Data about staff role (RN or other) and a yes/no question about past experience interacting with children with autism, Down syndrome, neurological conditions, mental retardation, or anxiety for the nurses, nursing assistants, and students were collected. Extra staff comments were also solicited. Demographics were collected, as well as past experience, knowledge, and fear of working with children with challenging behavior (10point Likert scale). Posteducation, the evaluation included knowledge and fear of working with children with challenging behavior (10-point Likert scale, $1=$ no knowledge, $10=$ much knowledge).

\section{Results}

In the first 18 months of the program, 604 health care providers completed both parts of the education. All 604 completed the Web-based evaluation surveys for the on-line portion of the education. However, data from the in-person instructor-led sessions were more limited $(n=42)$. Participants were RNs ( $n=346,57.8 \%$ ) and other (student nurses and nursing assistants; $n=253$, 42.2\%). Participants self-reported if they met the eight learning objectives related to preparation necessary for the prevention of and responding to challenging behavior (Table 1). Participant comments included the following: "engaging, interactive," "it was basic information," "important to know how to prevent escalated behavior because it is easier than trying to deal with escalated behavior ," "I feel I can handle them better now," and "I worked with...children (with autism)...everything we went over was so right!!"

In the second part (instructor-led portion) of the education, 42 nurses, students, and nursing assistants completed the pre and post questionnaires, addressing the two learning objectives: the learner will have (a) increased knowledge of challenging behaviors and (b) decreased fear of children with challenging behaviors. Of the 42 participants, 25 (59\%) reported past experience caring for children 
with challenging behaviors, whereas 17 (41\%) reported no past experience caring for children with challenging behaviors.

The main outcomes of the study are that after this instructor-led part of the education on challenging behaviors, participants' showed increased knowledge and decreased fear for working with children with developmental disabilities. The average rating for staff knowledge about how to care for children with challenging behavior increased from 5.5 to 8.7 ( $1=$ no knowledge, $10=$ a lot of knowledge), whereas average fear scores decreased from 3.2 to $2.7(1=$ no fear to $10=$ very fearful).

\section{Discussion}

The increased knowledge and decreased fear for the study participants are important and hopeful findings for a pilot hospital education program designing for working with children with developmental disabilities. No other existing program for training nursing staff was located in the literature. The education is needed to address safety concerns for nursing staff that literature shows may be hesitant to use restraints to limit a child's challenging behaviors and who are subsequently at risk for injury (Loo et al., 2009, Thorne, 2007).

Based on the evaluation of the first part of the education (on-line), the nursing staff learned communication strategies to prevent and manage challenging behaviors. Furthermore, staff members were able to learn at their convenience and pace because the materials were delivered to them online. Most of the staff participants strongly agreed that they could identify the need for the training (56.4\%), and a large percentage of staff strongly agreed that they could identify how parents can prepare the child for the hospital (49.8\%) and the stages of escalating behaviors (47.9\%). However, after the on-line education, only $40.1 \%$ of staff indicated strong agreement that they know how to prevent challenging behaviors, and only $42.1 \%$ knew what to do during the behaviors. The on-line education alone does not appear to be enough to develop confidence for staff to identify and respond to challenging behaviors. These findings match the principles of education that recommend providing relevant information, demonstration of knowledge, and the opportunity to practice and get feedback directly from instructors during training (Salas \& Cannon-Bowers, 2001). Therefore, the instructor-led session was critical for allowing staff the opportunity to develop the skills to prevent and manage challenging behaviors.

The participants in the instructor-led sessions perceived less fear about caring for children with developmental disabilities after the education, and they noted improved knowledge as well. Because only 25 (59\%) of the RNs reported past experience caring for children with challenging behavior and 17 (41\%) reported no past experience caring for children with challenging behaviors, an improvement in the knowledge is important for the nursing staff working with children. The education provides a first exposure to the strategies on behavior challenges management for many hospital staff members. Moreover, the education is needed given the high (17\%) prevalence of developmental disabilities (CDC, 2006) and their higher rate of hospital admissions than typically developing children (Liptak et al., 2006).

A decrease in fear along with the improvement in knowledge demonstrates the confidence that the training gives the participants to interact with children with developmental disabilities, now that they have strategies to prevent and manage challenging behaviors. This finding was expected based on the 
Bandura's (1977) self-efficacy theory, which predicted that role-play and vicarious experience improve confidence. Confident nursing staff are more likely to implement the strategies they learn in the education, which could lead to a reduction in the use of restraints by nursing staff. However, if principles in the program were not found to be working and a child presented with challenging behaviors endangering himself or herself or others, hospital staff should be instructed to consult hospital security. Security personnel may be able to assist with safe communication using the principles of verbal judo and safely restrain a child if needed.

\section{Limitations}

The evaluation of the pilot education has limitations. Evaluation data were collected for all staff $(N=$ 604 ) that completed the on-line sessions. However, data from the in person sessions were more limited $(n=42)$ because of constraints of time. An education initiative that includes all the supporting materials (just-in-time reference sheets, distraction items, social scripts, and environment modifications) described in this pilot merits a formal multisite study. The outcome measures could include changes in staff confidence, procedure cancelation rates, change in use of restraints, and staff injury rates.

\section{Interpretation}

Staff in other hospitals could benefit from a similar education program. They may also find similar results for increased knowledge and decreased fear for caring for children with developmental disabilities by training staff with a communication-based program based on the principles of effective education (Salas \& Cannon-Bowers, 2001) and self-efficacy theory (Bandura, 1977). Over time, new nursing staff, nursing students, and care partners can be trained during hospital orientation programs, as the time commitment for the education is relatively short ( 2 hours).

\section{Conclusions}

Children with developmental disabilities and the staff caring for them are at risk for injuries, cancelled appointments, and fear and dissatisfaction because the children may not be able to cope with the unpredictable hospital environment. Resources developed and made available to nursing staff and students included on-line and in-person education, just-in-time resource sheets, a coping kit of distraction items, social scripts and communication cards, and environmental modifications. The educational content focused on family-centered care, how to communicate to a child during the three stages of a tantrum, and the structured communication. An evaluation of the pilot nursing staff education revealed improved nursing staff knowledge and decreased fear about caring for children with developmental disabilities. Improved knowledge and decreased fear about caring for children with the potential for challenging behaviors comprise the first step toward preventing injury and canceled appointments/procedures. To this end, improved care for children with developmental disabilities begins before their arrival to the hospital and is interdisciplinary. 


\section{Acknowledgments}

The authors acknowledge Carol Klingbeil, MSN, CPNP; Deb Martinez, RN; Megan Massey, CCLS; Jennifer Drake, MS, RN; Gayle Kazmierczak; Patty Lamers; and Brian Herteen for their contribution in developing the education.

\section{References}

Allik et al., 2006. H. Allik, J.O. Larsson, H. Smedje. Health-related quality of life in parents of schoolage children with Asperger syndrome or high-functioning autism. Health \& Quality of Life Outcomes, 4 (2006), p. 1

Aylott, 2004. J. Aylott. Autism: Developing a strategy for nursing to prevent discrimination. British Journal of Nursing, 13 (2004), pp. 828-833

Bandura, 1977. A. Bandura. Social learning theory, Prentice Hall, Englewood Cliffs, NJ (1977)

Blake, 2010. Blake, K. (2010). Spectrum disorders a new generation of complex patients. Pennsylvania Nurse, 65(4), 9-11, 15.

Baker, 2008. J. Baker. No more meltdowns: Positive strategies for managing and preventing out-of control behaviors, Future Horizons Inc, Arlington, TX (2008)

Beard-Pfeuffer, 2008. M. Beard-Pfeuffer. Understanding the world of children with autism. RN, 71 (2008), pp. 40-46

Bellando and Lopez, 2009. J. Bellando, M. Lopez. The school nurse's role in treatment of the student with autism spectrum disorders. Journal for Specialists in Pediatric Nursing, 14 (2009), pp. 173182

Browne, 2006. M. Browne. Communication with the child who has autism spectrum disorder: A practical introduction. Paediatric Nursing, 18 (2006), pp. 14-17

Bruininks et al., 1997. R. Bruininks, R. Woodcock, R. Weatherman, H. Hill. Scales of Independent Behavior-Revised rolling, Riverside Publishing, Measdows, IL (1997)

Carbone et al., 2010. P. Carbone, D. Behl, V. Azor, N. Murphy. The medical home for children with autism specrum disorders: Parent and pediatrician perspectives. Journal of Autism \& Developmental Disorders, 40 (2010), pp. 317-324

Centers for Disease Control and Prevention, 2004. Centers for Disease Control and Prevention (CDC). Developmental disabilities (2004). Retrieved from. http://www.cdc.gov/ncbddd/dd/dd1.htm. Accessed January 14, 2011

Centers for Disease Control and Prevention (CDC), 2006. Centers for Disease Control and Prevention (CDC). How common are autism spectrum disorders (ASD)? (2006). Retreived from. http://www.cdc.gov/ncbddd/autism/asd common.htm. Accessed January 14, 2011

Debbaudt, 2009. D. Debbaudt. Patients with autism and other high risks: A growing challenge for healthcare security. Journal of Healthcare Protection Management, 25 (2009), pp. 14-26

Drake et al., in press. Drake, J., Johnson, N., Stonek, V., Martinez, D., \& Massey, M. (in press).

"Evaluation of a coping kit for children with challenging behaviors in a pediatric hospital". Pediatric Nursing.

Estes et al., 2009. A. Estes, J. Munson, G. Dawson, E. Koehler, X. Zhou, R. Abbott. Parenting stress and psychological functioning among mothers of preschool children with autism and developmental delay. Autism, 13 (2009), pp. 375-387

Fontaine and Gerardi, 2005. D. Fontaine, D. Gerardi. Healthier hospitals? Nursing Management, 36 (2005), pp. 34-44 
Gardner, 2001. M.R. Gardner. Understanding and caring for the child with Asperger syndrome. Journal of School Nursing, 17 (2001), pp. 178-184

Giarelli et al., 2005. E. Giarelli, M. Souders, J. Pinto-Martin, J. Bloch, S.E. Levy. Intervention pilot for parents of children with autistic spectrum disorder. Pediatric Nursing, 31 (2005), pp. 389-399

Gurney et al., 2006. J. Gurney, M. McPheeters, M. Davis. Parental report of health conditions and health care use among children with and without autism. Archives of Pediatric and Adolescent Medicine, 160 (2006), pp. 825-830

Gray, 1994. C. Gray. The new social story book, Future Horizons, Arlington, TX (1994)

Gray, 2012. C. Gray. The Gray Center for Social Learning and Understanding. Retrieved from. www.thegraycenter.org (2012). Accessed February 5, 2012

Hockenberry and Wilson, 2010. M. Hockenberry, D. Wilson. Wong's nursing care of infants and children, Elsevier, New York (2010)

Inglese, 2009. M.D. Inglese. Caring for children with autism spectrum disorder. Part II: Screening, diagnosis, and management. Journal of Pediatric Nursing, 24 (2009), pp. 49-59

Klaw, 2006. R. Klaw. Thoughtful responses to agitation, escalation, and meltdowns in individuals with autism spectrum disorder: A trining DVD (2006). Available for purchase at. http://www.rebeccaklaw.com/dvdsbooks.html

Kogan et al., 2008. M. Kogan, B. Strickland, S. Blumberg, G. Singh, J. Perrin, P. van Dyck. A national profile of the health care experiences and family impact of autism spectrum disorder among children in the United States. Pediatrics, 122 (2008), pp. e1149-e1158. Retrieved from. http://0-www.pediatrics.org.libus.csd.mu.edu/cgi/content/full/122/6/e1149

Lashley, 2009. J. Lashley. Autism spectrum disorders: A special needs subject response guide for police officers (2009). Retrieved September 14, 2011 from. http://www.autismsocietyofwa.org/main/wp-content/uploads/2011/04/Autism-Guide-forPolice-Officers-0311.pdf1

Liptak et al., 2006. G. Liptak, T. Stuart, P. Auinger. Health care utilization and expenditures for children with autism: Data from U.S. national samples. Journal of Autism and Developmental Disorders, 36 (2006), pp. 876-879

Loo et al., 2009. C. Loo, R. Graham, C. Hughes. Behaviour guidance in dental treatment of patients with autism spectrum disorder. International Journal of Pediatric Dentistry, 19 (2009), pp. 390398

Myers and Johnson, 2007. S.M. Myers, C.P. Johnson. Management of children with autism spectrum disorders. Pediatrics, 120 (2007), pp. 1162-1182

Newsom and Hovanitz, 2006. C. Newsom, C. Hovanitz. Autism spectrum disorders. E.J. Marsh, R.A. Barkley (Eds.), Treatment of Childhood Disorders (3rd ed.), Guilford Press, New York (2006), pp. 455-511

Raposa, 2009. K. Raposa. Behavioral management for patients with intellectual and developmental disorders. Dental Clinics of North America, 53 (2009), pp. 359-373

Salas and Cannon-Bowers, 2001. E. Salas, J.C. Cannon-Bowers. The science of training: A decade of progress. Annual Review of Psychology, 52 (2001), pp. 471-499

Scarpinato et al., 2010. N. Scarpinato, J. Bradley, K. Kurbjun, X. Bateman, B. Holtzer, B. Ely. Caring for the child with an autism spectrum disorder in the acute care setting. Journal for Specialists in Pediatric Nursing, 15 (2010), pp. 244-254

Smith-Myles and Southwick, 2005. B. Smith-Myles, J. Southwick. Asperger syndrome and difficult moments: Practical solutions for tantrums, rage and meltdowns, Autism Asperger Publishing Company (2005) 
Souders et al., 2002. M. Souders, K. Freeman, D. DePaul, S.E. Levy. Caring for children and adolescents with autism who require challenging procedures. Pediatric Nursing, 28 (2002), pp. 555-562

Tarbox et al., 2003. R.S.F. Tarbox, M.D. Wallace, L. Williams. Assessment and treatment of elopement:

A replication and extension. Journal of Applied Behavior Analysis, 36 (2003), pp. 239-244

The Joint Commission, 2011. The Joint Commission. National safety standards (2011). Retrieved from.

http://www.jointcommission.org/assets/1/6/2011 NPSGs HAP.pdf. Accessed January 14, 2011

Thompson and Jenkins, 2004. G. Thompson, J. Jenkins. Verbal judo: The gentle art of persuasion, Harper Collins, Collorado Springs, Quill (2004)

Thorne, 2007. A. Thorne. Are you ready to give care to a child with autism? Nursing, 37 (2007)

Tucker et al., 2008. S. Tucker, D. Derscheid, S. Odegarden, M. Olson. Evidence-based training for enhancing psychiatric nurses' child behavior management skills. [research]. Journal for Nurses in Staff Development, 24 (2008), pp. 75-85

Valente, 2004. S. Valente. Autism. Journal of the American Psychiatric Nurses Association, 10 (2004), pp. 236-243 